\title{
STRENGTH AND STIFFNESS OF ROLL FORMED RECTANGULAR HOLLOW SECTIONS OF VARIOUS MANUFACTURING OPTIONS
}

\author{
Kukhar V. V.
}

\section{INTRODUCTION}

Rectangular structural hollow sections (RHS) are great importance for much purposes, such as construction (load-bearing frames, columns, posts) and reinforced concrete structures, uPVC window systems of buildings and constructions, some areas of civil or mechanical engineering, shipbuilding, etc. ${ }^{1}$. Due to the prevalence and increasing demand for structural section, the requirements for the geometric parameters and strength of such products are becoming more stringent, for that the different standards have been developed in the European Union and most developed world countries ${ }^{2}$.

For the manufacture of structural sections with required service properties different fabrication methods are used ${ }^{1}$ : skew roll piercing process, pilger process, Fretz-Moon pipe process, induction welding process, spirally bent strip welding. Hot-finished process (HFP) and cold-formed process (CFP) is the most common manufacturing for $\mathrm{RHS}^{3}$. These consist in the roll-forming of circular tube from a strip, welding of edges and reforming into rectangular tube section (round to square or rectangular section forming) with heating (HFP) or without heating (CFP), respectively. Recently, the direct-forming process (DFP) for RHS has been very justified and economical. This process of directly forming to square or closed rectangular section by sequential bending on multi-roll roll-forming mills with longitudinally welding of edges at finishing have proved to be satisfactory ${ }^{4}$.

${ }^{1}$ Wardenier J., Packer J. A., Zhao X.-L., van der Vegte G. J. Hollow sections in structural applications. CIDECT. Geneva, Switzerland, 2010.

${ }^{2}$ Huang Y., Young B. Experimental and numerical investigation of cold-formed lean duplex stainless steel flexural members. Thin-walled Structures. 2013. Vol. 73. P. 216-228. DOI: https://doi.org/10.1016/j.tws.2013.07.019.

${ }^{3}$ Sun M., Packer J. A. Direct-formed and continuous-formed rectangular hollow sections. Comparison of static properties. Journal of Constructional Steel Research. 2014. Vol. 92. P. 67-78. DOI: https://doi.org/10.1016/j.jcsr.2013.09.013.

${ }^{4}$ Sun M., Packer J. A. Direct-formed and continuous-formed rectangular hollow sections. Comparison of static properties. Journal of Constructional Steel Research. 2014. Vol. 92. P. 67-78. DOI: https://doi.org/10.1016/j.jcsr.2013.09.013. 
The improvement of designs, process of production and quality control of these products is constantly given considerable attention due to their high importance and adaptation to different ranges of use. Therefore, the development of methods of modeling of the section behavior of various (including improved) structures remains extremely relevant, because allows to identify the advantages and disadvantages of new solutions and develop recommendations for improving the processes of manufacturing structural sections. Research on stiffness of structural sections is conducted by bending and torsion tests.

The bending tests are carried out according to standardized methods by loading sections by four-point or three-point scheme ${ }^{5}$. It is quite common to combine experimental tests with computer simulation of the test process ${ }^{6}$. The latter requires an account of the physical conditions of the test deformation, the complexity of the geometric shapes of the section and the material properties of the specimens to be as accurate as possible, which presents certain difficulties. Studies of the complex characteristics of strength and stiffness are performed for sections of different shapes (open and closed), of different materials (including non-metal), non-welded and welded, taking into account the complexity of the shape of the final product, location and load in real construction ${ }^{7}$. This defines the deflection values as the characteristics of sections stiffness, and magnitudes of stresses as characteristics of sections strength. Certain progress has been made in testing and modeling the section loading process by three-point bending, when the section is viewed as a beam supported on round pins) and loaded along the axis of symmetry by a rounded loading pin. As a result, the behavior of the walls and webs of the section, different buckling shapes ${ }^{8}$, revealed critical values of forces and stresses have been described. The main result of the tests on the stiffness of the sections is to obtain a graphical dependence of the deflection values on the load force ${ }^{5}$. In some cases, instead of the deflection values, they determine the parameters of the beam

${ }^{5}$ Bock M., Arrayago I., Real E. Experiments on cold-formed ferritic stainless steel slender sections. Journal of constructional steel research. 2015. Vol. 109. P. 13-23. DOI: https://doi.org/10.1016/j.jcsr.2015.02.005.

${ }^{6}$ Podstawka A., Kovar M., Foglar M., Kristek V. Analytical and Statistical Evaluation of FRC Bending Tests Layouts. Advanced Materials Research. 2015. Vol. 1106. P. 118-121. DOI: https://doi.org/10.4028/www.scientific.net/AMR. 1106.118.

${ }^{7}$ Kuchta K., Tylek I. Rational application of hot finished rectangular hollow sections in steel structures. MATEC Web of Conferences. 2018. Vol. 163. P. 07005. DOI: https://doi.org/10.1051/matecconf/201816307005.

${ }^{8}$ Bock M., Arrayago I., Real E. Experiments on cold-formed ferritic stainless steel slender sections. Journal of constructional steel research. 2015. Vol. 109. P. 13-23. DOI: https://doi.org/10.1016/j.jcsr.2015.02.005. 
curvature $^{9}$ at loading or analytically calculate the bending angle between the bent beam and the horizontal axis ${ }^{10}$. It is particularly difficult to consider the multilayer sections when using coated specimens.

Torsion test is carried out for structural sections of various designs and materials ${ }^{11}$. Modern packages for finite element modeling (FEM) make it possible to evaluate the behavior of sections for both static torsion and torsion with the application of various types of loads ${ }^{12}$. The main evaluation criterion is to identify the dependence of torsion angle (or equivalent displacement) on the applied torque (or force impact) ${ }^{13}$. For basic cases static conditions are usually investigated.

For the production and, accordingly, for testing of structural sections, galvanizing carbon steel is most often used as a material. When testing galvanized steel sections, the thickness of the zinc coating is generally neglected as an absolutely thin film. Changing the design of the structural section $^{14}$ or introducing of consistent direct-forming with longitudinal welding of the edges of the closed section requires evaluation of the indices of stiffness and strength (stresses) of RHS to identify the advantages or disadvantages of new processes.

\section{Research objectives}

There is a certain enterprise that produces of RHS by direct-forming (DF-RHS) for reinforcing of uPVC window (Fig. 1). According to production plans, it is desirable to establish the series release of RHS by direct-forming with welding of edges (DFW-RHS) in longitudinal seam.

${ }^{9}$ Wang J., Afshan S., Gkantou M., Theofanous M., Baniotopoulos C., Gardner L. Flexural behaviour of hot-finished high strength steel square and rectangular hollow sections. Journal of Constructional Steel Research. 2016. Vol. 121. P. 97-109. DOI: https://doi.org/10.1016/j.jcsr.2016.01.017.

${ }^{10}$ Larour P., Hackl B., Leomann F., Benedyk K. Bending angle calculation in the instrumented three-point bending test. Proc. IDDRG 2012: Lightweight: Possibilities \& Challenges. Mumbai, India, 2012. P. 203-215.

${ }^{11}$ Devi S. V., Singh T. G., Singh K. D. Cold-formed steel square hollow members with circular perforations subjected to torsion. Journal of Constructional Steel Research. 2019. Vol. 162. P. 105730. DOI: https://doi.org/10.1016/ j.jcsr.2019. 105730.

${ }^{12}$ 10. Gunalan S., Mahendran M. Improved design rules for fixed ended cold-formed steel columns subject to flexural-torsional buckling. Thin-Walled Structures. 2013. Vol. 7. P. 1-17. DOI: https://doi.org/10.1016/j.tws.2013.06.013.

${ }^{13}$ Devi S. V., Singh T. G., Singh K. D. Cold-formed steel square hollow members with circular perforations subjected to torsion. Journal of Constructional Steel Research. 2019. Vol. 162. P. 105730. DOI: https://doi.org/10.1016/j.jcsr.2019. 105730.

${ }^{14}$ Castellucci M. A., Pillinger I., Hartleya P., Deeley G. T. The optimisation of cold rolled formed products. Thin-Walled Structures. 1997. Vol. 29(1-4). P. 159-174. DOI: https://doi.org/10.1016/S0263-8231(97)00020-7. 
Strength and stiffness (stresses and displacements) of the sections should be evaluated by bending and torsion tests for estimate of material consumption reducing for improved RHS, as a practical value of the research. The results of the study of the behavior of sections of the same shape, but different variants of manufacture, after the tests will allow to establish dependencies between the force $\&$ torque magnitudes and deflection $\&$ displacement, to estimate the section deflect or twist distortions at the same load, and to compare the stresses in the webs, which is a scientific originality of research.

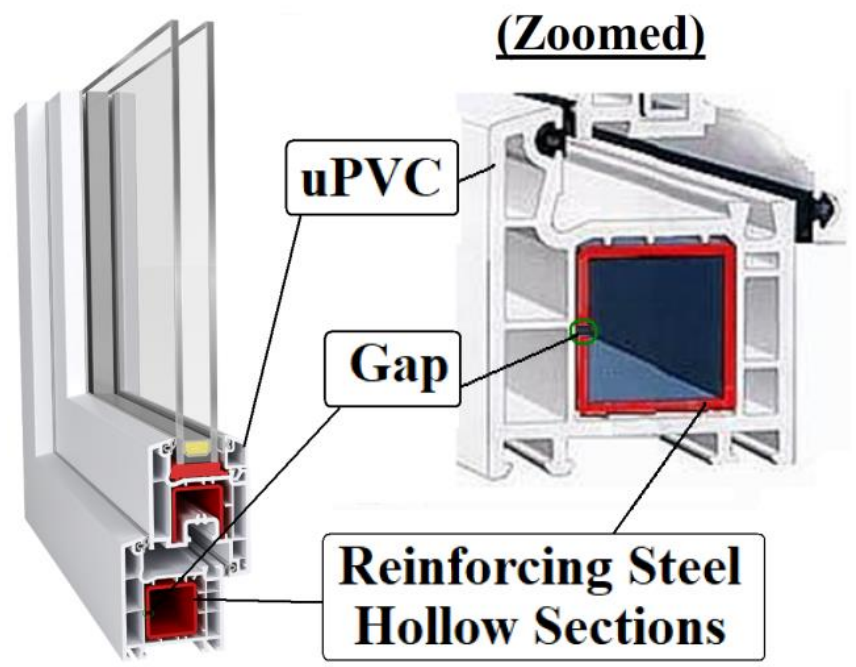

Fig. 1. Reinforcing RHS in uPVC window system

The aim of this work is to determine, using of three-point bending (by testing and finite-element modeling) and torsion tests (by finite-element modeling), differences in the strength and stiffness performance characteristics of sections with $40 \mathrm{~mm} \times 50 \mathrm{~mm}$ width of webs, manufactured by directly multi-roll forming of steel beam:

(a) 40*50 DF-RHS - as semi-closed section with a gap between the edges not more than $0.5 \mathrm{~mm}$, formed along a middle of the web (face) with a size of $40 \mathrm{~mm}$;

(b) $40 * 50 \mathrm{DFW}$-RHS - as closed sections and subsequent welding of the edges with the longitudinal weld on the middle of the web (face) with a size of $50 \mathrm{~mm}$.

Comparing these types of RHS with the gap and the weld will allow to see differences in the behavior of products of similar cross-section and different variants of manufacture with differences in thickness, and, as a 
consequence, to evaluate the prospects of reducing the material consumption of the DFW-RHS while ensuring equivalent stiffness.

\section{Simulation of three-point bending and torsion tests}

\subsection{Methodology of research}

The research of the RHS stress-strain state was performed on a solidstate deformable model using the CAD/CAE systems of SolidWorks. The geometric parameters of the model are fully consistent with the full-scale specimens (Fig. 2) and are made in a scale of 1:1 (for geometric similarity). The simulation did not take into account the dead weight of the specimen. As an assumption, a RHS wall with weld was considered as solid body without discontinuities, but with insignificant lateral longitudinal cut in the middle of the external web face. The study of the stress-strain state was carried out with loading options for three-point bending (I) and torsion (II).

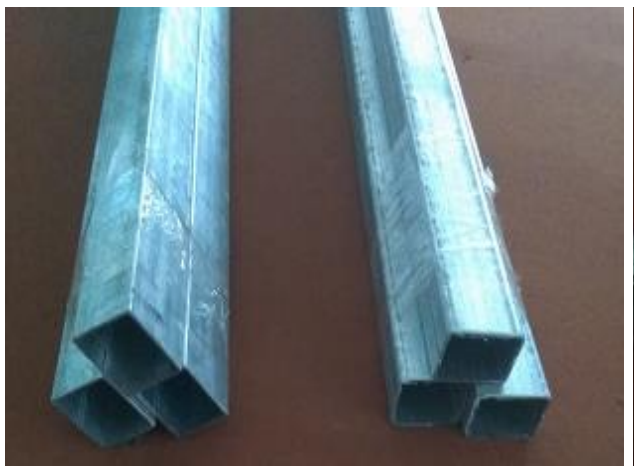

$a$
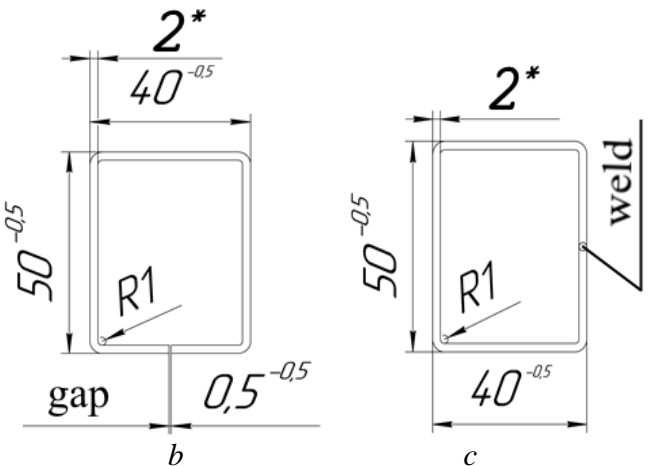

Fig. 2. Delivered RHS for research (a), DF-RHS(b) and DFW-RHS (c) with webs of $50 \mathrm{~mm} \times 40 \mathrm{~mm}\left({ }^{*} \mathrm{t}=2 \mathrm{~mm}-\right.$ nominal thickness of the section wall) 
For each option, diagrams of equivalent stresses and linear deflections in the model were determined. The calculated loads and their combinations were taken such that they correspond to the experiment on full-scale specimens.

The specimen models under research: (i) DF-RHS with cross section $40 \mathrm{~mm} \times 50 \mathrm{~mm}$ and thickness of the wall $\mathrm{t}=1.93 \mathrm{~mm}$; (ii) DFW-RHS with cross section $40 \mathrm{~mm} \times 50 \mathrm{~mm}$ and thickness of the wall $\mathrm{t}=1.84$ $\mathrm{mm}$; (iii) DFW-RHS with cross section $40 \mathrm{~mm} \times 50 \mathrm{~mm}$ and thickness of the wall $\mathrm{t}=0.7 \mathrm{~mm}$ (validation of results). Plain carbon steel was selected from the standard material library as model material. The specimen's own weight was not taken into account at calculating these models. In order to find solutions for reducing the RHS material consumption, it is important to have a general picture of the stress-strain state. Obtaining this data is possible by creating a calculated threedimensional model. To determine the actual stress-strain state, FEM was used, which was implemented in the CAD/CAE system environment. A finite element grid was created by "Simulation" means. Obviously, lower stresses, deflection and twist displacement correspond to the strengthliest and stiffest section.

\subsection{Results and discussion}

\subsubsection{Three-point bending}

Model of specimen was placed horizontally, bottom web is simply (freely) supported on supporting pins located at the distance of $1000 \mathrm{~mm}$ (Fig. 3). That allowed to simulate the process of specimen rotation relative to the supported pins during loading. The finite element mesh of the specimen model is shown in Fig. 3(b). Since the external load acting on the specimen is transmitted through the loading pin, such element with a diameter of $11.8 \mathrm{~mm}$ was taken into account in the model (Fig. 3(c)). The most unfavorable loading options for RHS were considered, leading to maximum deflections at the same force, i.e. loading was acting on a web of $50 \mathrm{~mm}$, see Fig. 3(d),(e). Thus, if DF-RHS was loaded, then the gap was on lateral web of $40 \mathrm{~mm}$; if DFW-RHS was loaded, then the weld was at the bottom web. The applied load $P(50)=500 \mathrm{~N}$ was act as static in the midpoint between the support pins, at an equal distance of $500 \mathrm{~mm}$ (Fig. 3).

The simulation results are given in Fig. 4 - Fig. 6. 

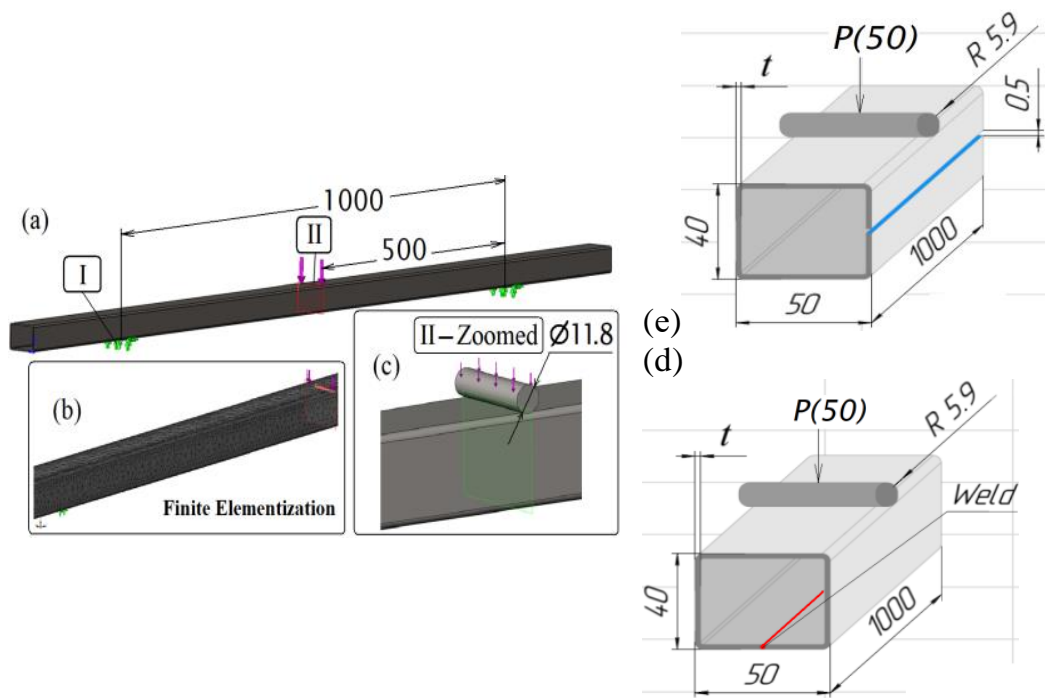

Fig. 3. Solid-state model of RHS (a) with supporting (I) and loading (II) pins, illustration of left part finite elementization (b), load acting (c) on DF-RHS (d) and DFW-RHS (e) at modeling
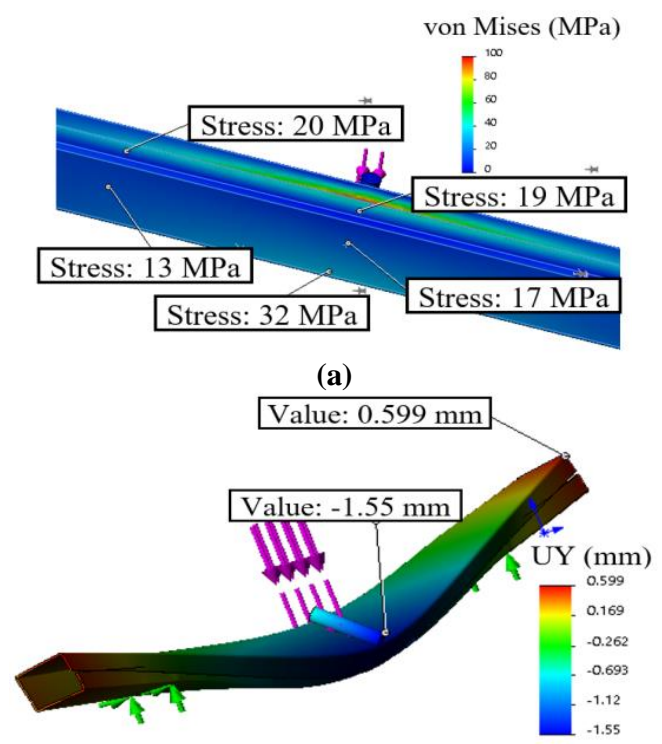

(b)

Fig. 4. Stresses in the bottom web (a) and deflections (b) of $40 * 50$ DF-RHS, $\mathrm{t}=\mathbf{1 . 9 3} \mathbf{~ m m}$ 


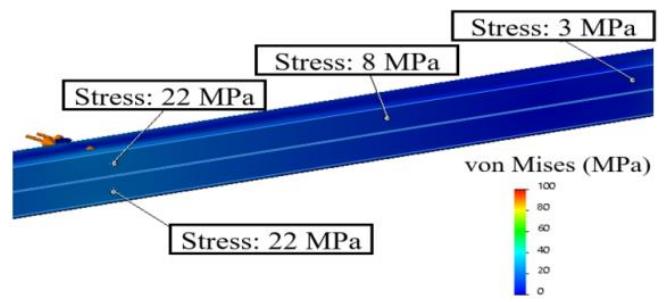

(a)

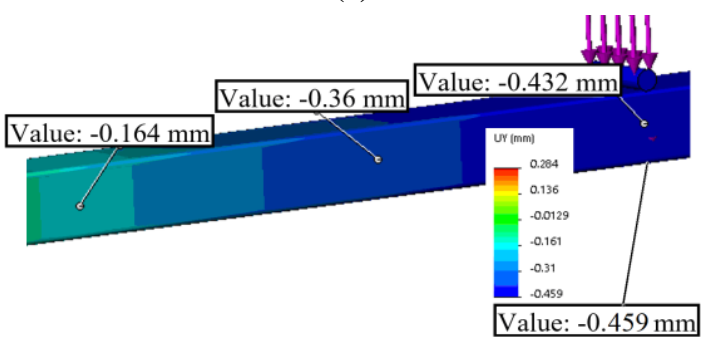

(b)

Fig. 5. Stresses in the bottom web (a) and deflections (b) of 40*50 DFW-RHS, $\mathrm{t}=\mathbf{1 . 8 4} \mathbf{~ m m}$

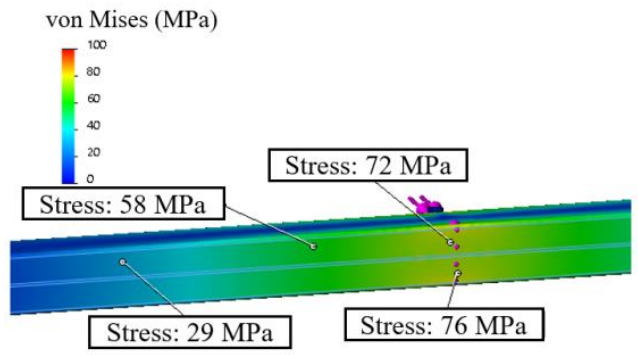

(a)

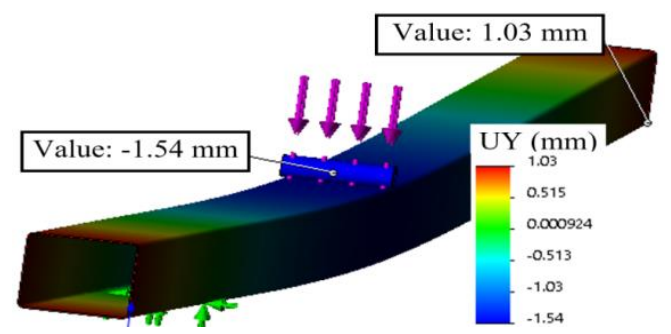

(b)

Fig. 6. Stresses in the bottom web (a) and deflections (b) of $40 * 50 \mathrm{DFW}$-RHS, $t=0.7 \mathrm{~mm}$ 
The following was established, as a result of the analysis results of stressstrain state modelling for identical loading schemes and equivalent points of sections:

(i) DFW-RHS with $\mathrm{t}=1.84 \mathrm{~mm}$ compared to DF-RHS with $\mathrm{t}=1.93 \mathrm{~mm}$ has higher strength. Maximum values of equivalent stress in DFW-RHS with $\mathrm{t}=1.84 \mathrm{~mm}$ were $22 \mathrm{MPa}$ (Fig. 5(a)), and in DF-RHS with $\mathrm{t}=1.93 \mathrm{~mm}-$ $32 \mathrm{MPa}$ (Fig. 4(a));

(ii) DFW-RHS with $\mathrm{t}=1.84 \mathrm{~mm}$ compared to DF-RHS with $\mathrm{t}=1.93 \mathrm{~mm}$ has higher stiffness. Maximum deflection for DFW-RHS with $\mathrm{t}=1.84 \mathrm{~mm}$ were $f=0.432 \mathrm{~mm}$ (Fig. 5(b)), and for DF-RHS with $\mathrm{t}=1.93 \mathrm{~mm}-f=1.55$ mm (Fig. 4(b));

(iii) DFW-RHS with $\mathrm{t}=0.7 \mathrm{~mm}$ compared to DF-RHS with $\mathrm{t}=1.93 \mathrm{~mm}$ has a less strength, since maximum equivalent stress in DFW-RHS with $\mathrm{t}=0.7 \mathrm{~mm}$ were $76 \mathrm{MPa}$ (Fig. 6(a)), and in DF-RHS with $\mathrm{t}=1.93 \mathrm{~mm}-$ $32 \mathrm{MPa}$ (Fig. 4(a)). But in this case, the resulting stresses are still much smaller than the yield stress of a given carbon steel $\left(y_{\mathrm{s}}=175-195 \mathrm{MPa}\right)$;

(iiii) DFW-RHS with $\mathrm{t}=0.7 \mathrm{~mm}$ compared to DF-RHS with $\mathrm{t}=1.93 \mathrm{~mm}$ has slightly greater or equal stiffness, i.e. maximum deflection for DFW-RHS with $\mathrm{t}=0.7 \mathrm{~mm}$ were $f=1.54 \mathrm{~mm}$ (Fig. 6(b)), and for DF-RHS with $\mathrm{t}=1.93 \mathrm{~mm}-f=1.55 \mathrm{~mm}$ (Fig. 4(b)).

\subsubsection{Torsion}

Solid-state models of specimens of considered RHS with a length of $1000 \mathrm{~mm}$ were used in the torsion test modeling. One end of specimen model was fixed at the simulation and torque of $\mathrm{T}=50,000 \mathrm{~N} \cdot \mathrm{mm}$ was applied to the other end. The twist displacement value ${ }^{15}$ was estimate for each RHS design, i.e. measured which travel path at the farthest point from the axis of section rotation. Simulation results in the form of distribution of equivalent stresses and twisting displacements for different RHS design are shown in Fig. 7-9.

${ }^{15}$ Yoon K., Lee Y., Lee P.-S. A continuum mechanics based 3-D beam finite element with warping displacements and its modeling capabilities. Structural Engineering and $\begin{array}{llll}\text { Mechanics. 2012. Vol. 43(4). P. 411-437. DOI: https://doi.org/10.12989/ } & \text { 2 }\end{array}$ sem.2012.43.4.411. 


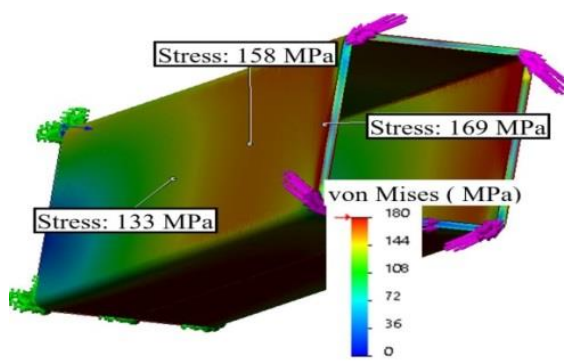

(a)

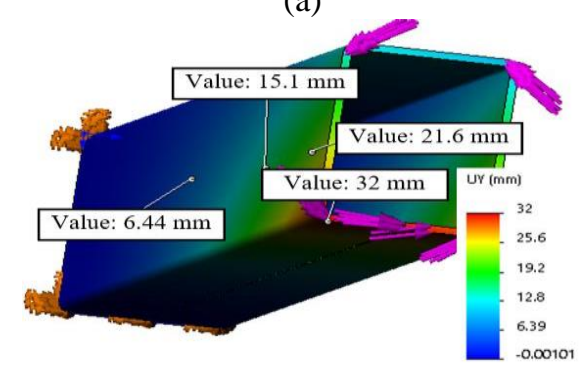

(b)

Fig. 7. Stresses (a) and twist displacements (b) of 40*50 DF-RHS, $t=1.93 \mathrm{~mm}$

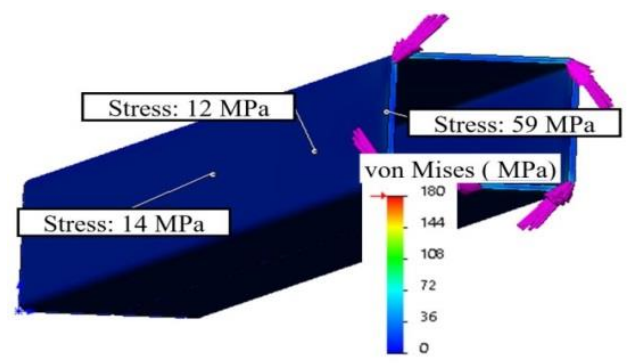

(a)

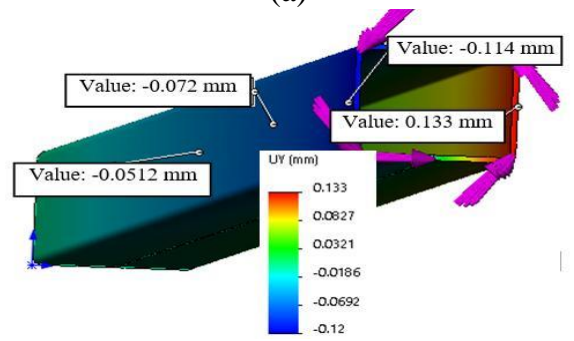

(b)

Fig. 8. Stresses (a) and twist displacements (b) of 40*50 DFW-RHS, $t=1.84 \mathrm{~mm}$ 


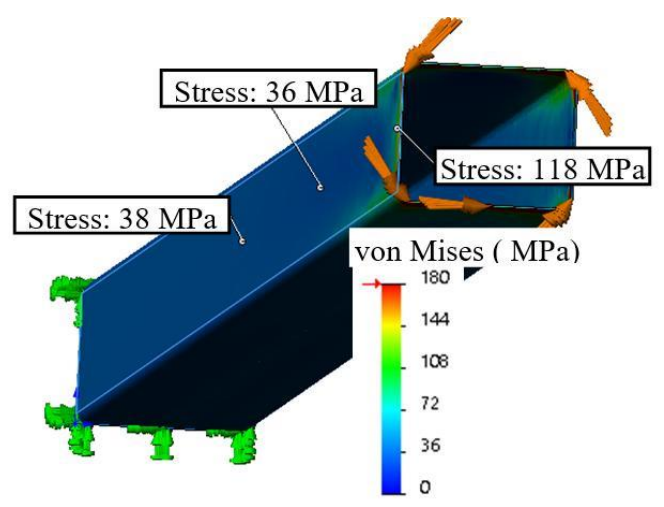

(a)

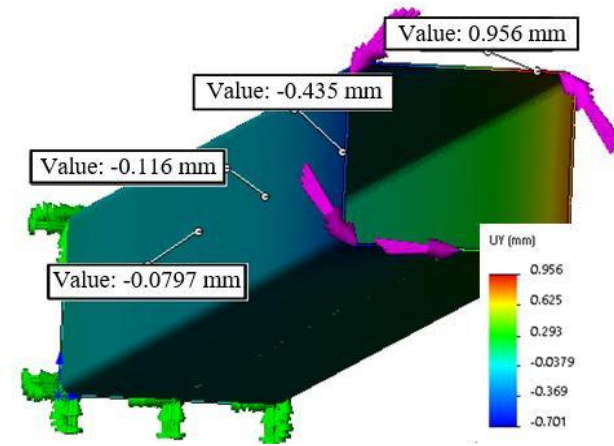

(b)

Fig. 9. Stresses (a) and twisting displacements (b) of 40*50 DFW-RHS, $\mathrm{t}=0.7 \mathrm{~mm}$

As a result of modeling the torsion test and analysis of the stress-strain state at the same torques, it should be concluded:

(i) DFW-RHS with $\mathrm{t}=1.84 \mathrm{~mm}$ is more strength than with DF-RHS with $\mathrm{t}=1.93 \mathrm{~mm}$. The maximum equivalent stress in DFW-RHS with $\mathrm{t}=1.84 \mathrm{~mm}$ were $59 \mathrm{MPa}$ (Fig. 8(a)), and in DF-RHS with $\mathrm{t}=1.93 \mathrm{~mm}-$ $169 \mathrm{MPa}$ (Fig. 7(a)), respectively;

(ii) DFW-RHS with $\mathrm{t}=1.84 \mathrm{~mm}$ is more stiff compared to DF-RHS with $\mathrm{t}=1.93 \mathrm{~mm}$. The maximum values of twist displacements for DFW-RHS with $\mathrm{t}=1.84 \mathrm{~mm}$ were $0.133 \mathrm{~mm}$ (Fig. 8(b)), and for DF-RHS with $\mathrm{t}=1.93 \mathrm{~mm}-32 \mathrm{~mm}$ (Fig. 7(b)), respectively;

(iii) DFW-RHS with $\mathrm{t}=0.7 \mathrm{~mm}$ is more strength than DF-RHS with $\mathrm{t}=1.93 \mathrm{~mm}$. The maximum values of equivalent stress in DFW-RHS with $\mathrm{t}=0.7 \mathrm{~mm}$ were $118 \mathrm{MPa}$ (Fig. 9(a)), and in DF-RHS with $\mathrm{t}=1.93 \mathrm{~mm}-$ $169 \mathrm{MPa}$ (Fig. 7(a)), respectively; 
(iiii) DFW-RHS with $\mathrm{t}=0.7 \mathrm{~mm}$ is more stiff compared to DF-RHS with $\mathrm{t}=1.93 \mathrm{~mm}$. The maximum twist displacement for DFW-RHS with $\mathrm{t}=0.7 \mathrm{~mm}$ were $0.956 \mathrm{~mm}$ (Fig. 9(b)), and for DF-RHS with $\mathrm{t}=1.93 \mathrm{~mm}-$ $32 \mathrm{~mm}$ (Fig. 7(b)), respectively.

\section{Three-point bending test experiment}

\subsection{Material of research}

For the experimental study, the sections of different manufacture (see Fig. 2 (b),(c)) were pre-examined and prepared for testing. The sections did not have any visible defects. From each type of section three specimens of RHS with a length of $1000 \mathrm{~mm}$ were cut out. The electronic caliper "Digital caliper A46", which was metrologically verified within the specified time, was used to measure the thickness. Ten measurements of the wall thickness of the specimens for each type of section were performed and statistical data processing was performed. Statistical verification of the adequacy of these experiments' description was performed according to the F-test, and the verification of experiment reproducibility was performed according to Cochran's test. It was established that the DF-RHS with a cross section of $50 \mathrm{~mm} \times 40 \mathrm{~mm}$ have an average wall thickness of $1.936 \mathrm{~mm}$, and the DFW-RHS with a cross section of $50 \mathrm{~mm} \times 40 \mathrm{~mm}$ have an average wall thickness of $1.843 \mathrm{~mm}$.

The main determining parameter characterizing the stiffness of the section is its deflection on three-point bending. The method of three-point bending was chosen for testing (Fig. 10). According to the principle indicated in Fig. 10, a test methodology using the experimental installation shown in Fig. 11 was developed. To load the section by three-point bending through a cylindrical spacer with a radius of $5.9 \mathrm{~mm}$, a tensile machine UMM-10 with a maximum load of $100 \mathrm{kN}$ was used. The deflection of the section was recorded with a mechanical dial gauge from the exemplary portable dynamometer DOSM-33 (Fig. 12). To detect these indicators of force $P$, a scale built in the UMM-10 was used, the change of indices throughout the experiment was recorded by a set camera in continuous recording mode (see Fig. 11).

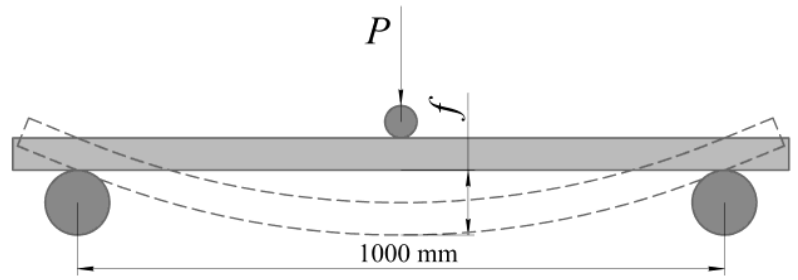

Fig. 10. Scheme of RHS bending by three-point bending 


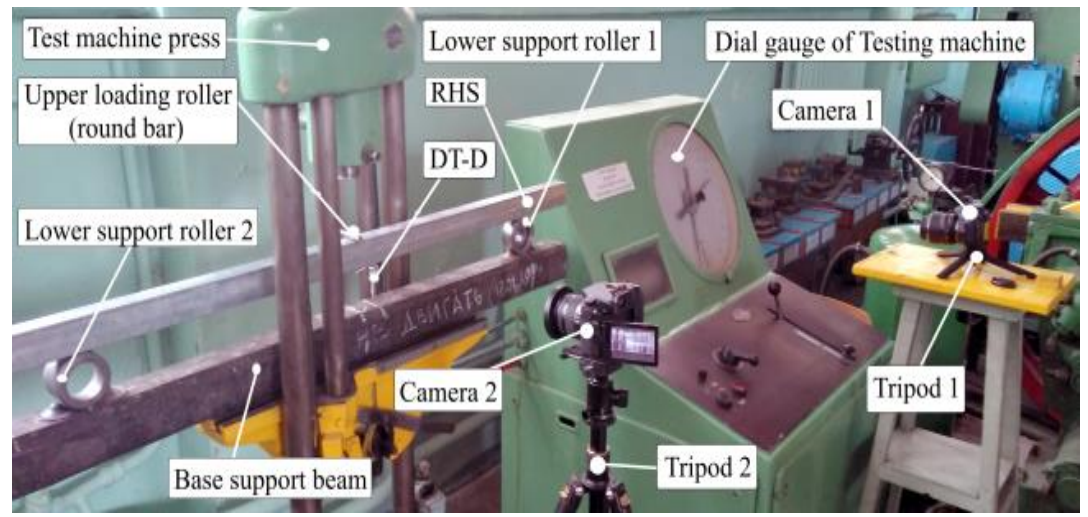

Fig. 11. Installation for experimental study
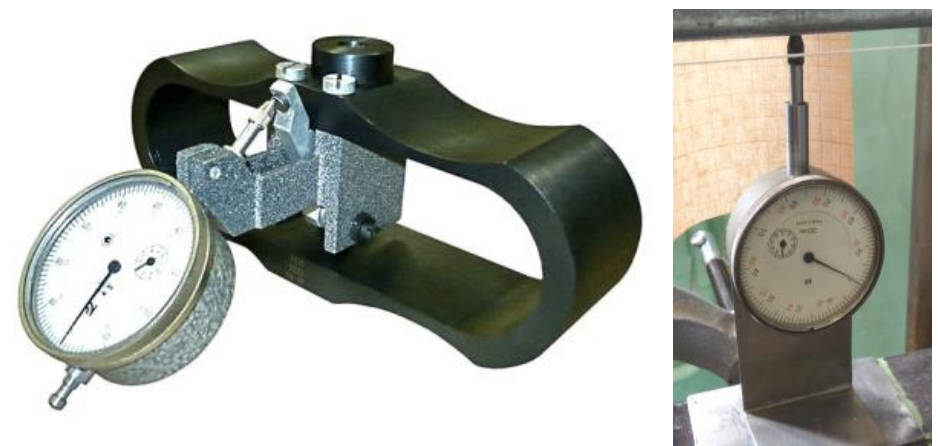

Fig. 12. Exemplary portable dynamometer DOSM-33 (left) and section deflection indices $f$ (right)

The same scheme was used to monitor the deflection of section $f$, capturing the gauge data using a second high-resolution camera. $50 \mathrm{~mm}$ web load (force $P(50)$ ) and $40 \mathrm{~mm}$ web load (force $P(40)$ ) were applied. Three fully recorded trials were conducted for each section type and cross section. The "DaVinci Resolve 15" software (to synchronize the operation of both cameras) and the Microsoft Excel options were used to process the results of the force and deflection experiment during three-point bending.

\subsection{Results and discussion}

The data obtained from the video made it possible to compare the synchronized changes in the force $P$ and the deflection of the section $f$ over time, that were used to build the graphical dependencies shown in Fig. 13 and Fig. 14. 


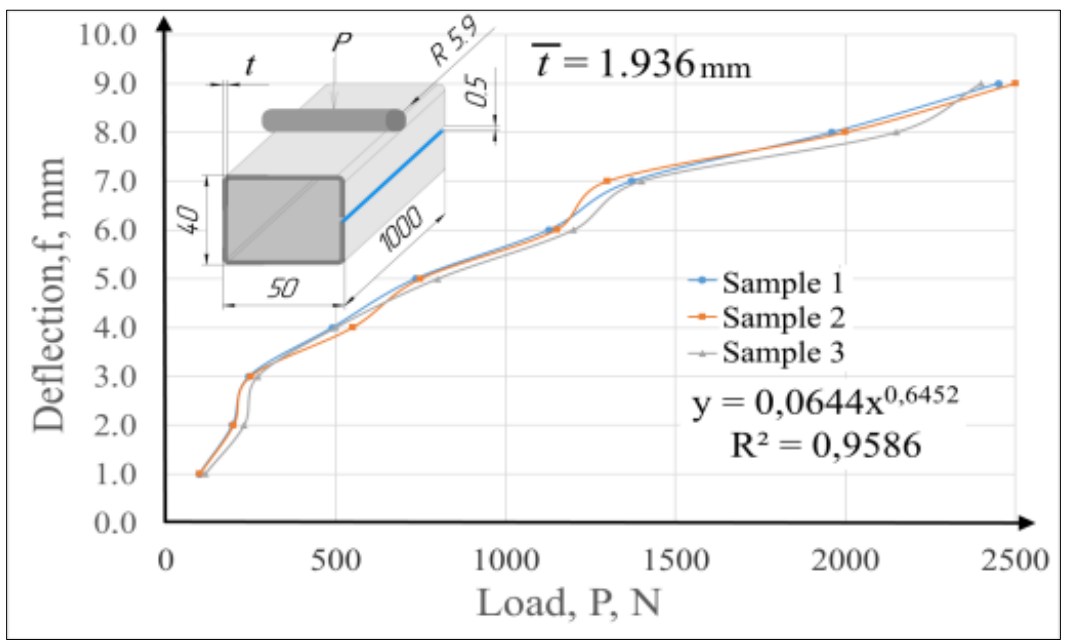

(a)

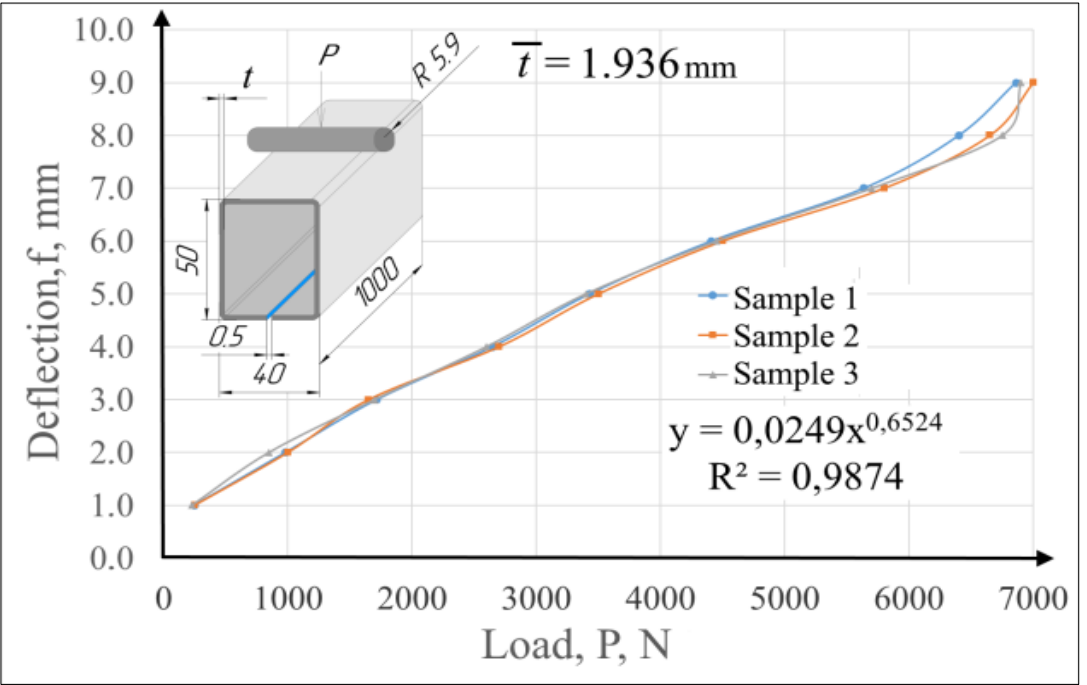

(b)

Fig. 13. Experimental graph of the results of the tests on the three-point bending of DF-RHS with cross section $40 \mathrm{~mm} \times 50 \mathrm{~mm}(t=1.936 \mathrm{~mm})$

by concentrated force: (a) application of force $\boldsymbol{P ( 5 0 )}$

/to the larger edge of the section; (b) application of force $P(40)$ to the smaller edge of the section 


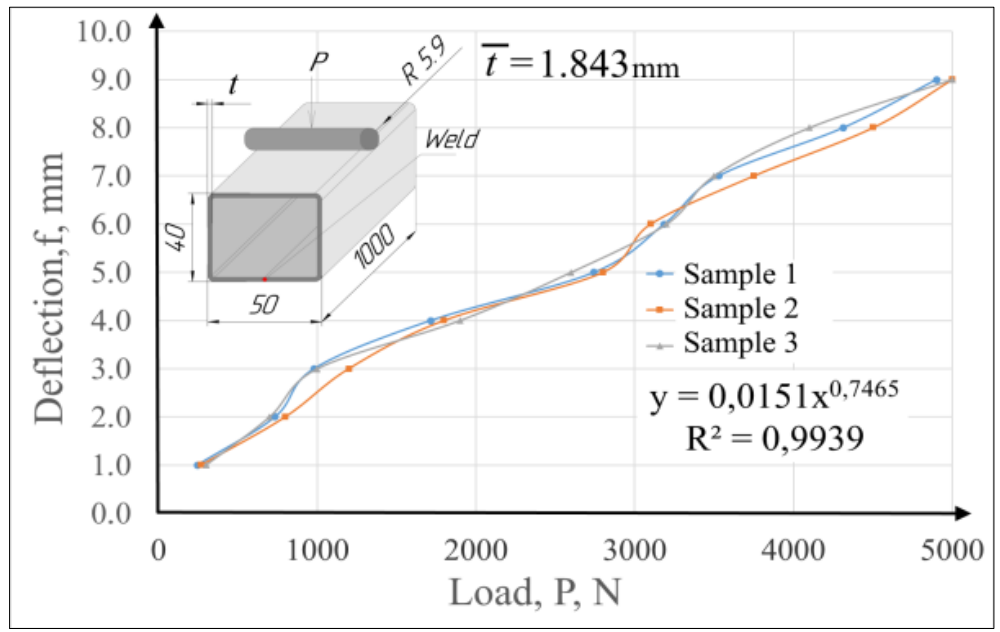

(a)

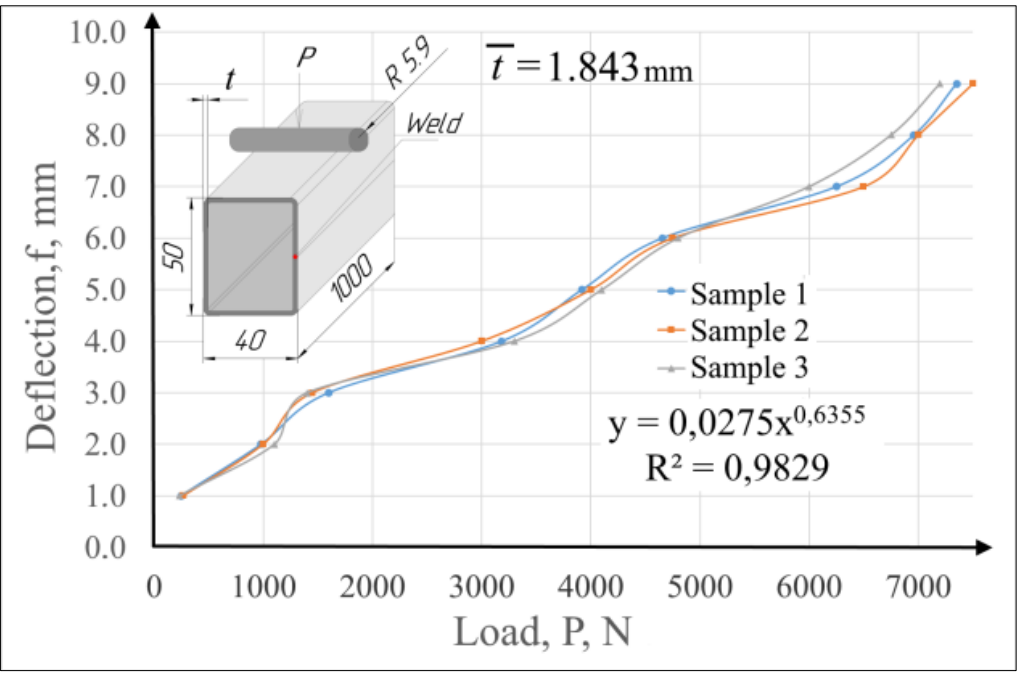

(b)

Fig. 14. Experimental graph of the results of the tests on the three-point bending of DFW-RHS with cross section $40 \mathrm{~mm} \times 50 \mathrm{~mm}=1.843 \mathrm{~mm}$ ) by concentrated force: (a) application of force $P(50)$ to the larger edge of the section; (b) application of force $P(40)$ to the smaller edge of the section 
After processing the obtained graphical dependences of the deflection on the load force, regression equations were obtained. It was established that the functional dependence of the deflection on the load value is most accurately described by the power equations with the coefficient of determination $\mathrm{R}^{2}>0.95$ :

- for DF-RHS:

$$
\begin{aligned}
& f=0.0644 \cdot P(50)^{0.6452} ; \\
& f=0.0249 \cdot P(40)^{0.6524} ;
\end{aligned}
$$

- for DFW-RHS:

$$
\begin{aligned}
& f=0.0151 \cdot P(50)^{0.7465} ; \\
& f=0.0275 \cdot P(40)^{0.6355} .
\end{aligned}
$$

\section{CONCLUSIONS}

Based on the FEM using, RHS with a cross section of $40 \mathrm{~mm} \times 50 \mathrm{~mm}$ was investigated, that have a difference in manufacturing options by direct-forming (DF-RHS) with longitudinal gap and direct-forming with the next edge welding (DFW-RHS) into longitudinal weld seam. It was found that the existing additional initial differences affect to the results of research: (a) the gap at DF-RHS is located in the middle of the width of the smaller web $(40 \mathrm{~mm})$, and the weld seam at DFW-RHS is in the middle of the width of the larger web $(50 \mathrm{~mm})$; (b) the average wall thickness of DF-RHS is $t=1.93 \mathrm{~mm}$, and DFW-RHS is $\mathrm{t}=1.84 \mathrm{~mm}$ (i.e. the difference is $4.8 \%$ ). Based on the proposed FEM methodology for three-point bending test and torsion test, the distribution of equivalent stresses and displacements in RHS was analyzed. It is shown that the use of DFW-RHS as a reinforcing beam has advantages (especially in terms of stiffness) compared to DF-RHS. It was found that with identical loading schemes, DF-RHS with $\mathrm{t}=1.93 \mathrm{~mm}$ has the same stiffness characteristics as a DFW-RHS with $t=0.7 \mathrm{~mm}$, i.e. it becomes possible to reduce metal consumption by $62 \%$. Strength of DFW-RHS with $\mathrm{t}=0.7 \mathrm{~mm}$ are worse than DF-RHS with $\mathrm{t}=1.93 \mathrm{~mm}$ due to a significant difference in wall thickness, however, the maximum bending stresses in DFW-RHS with $\mathrm{t}=0.7 \mathrm{~mm}$, equal to $77 \mathrm{MPa}$, do not exceed the yield strength of the section steel (ys $=175-195 \mathrm{MPa}$ ). That is, despite the smaller wall thickness, DFW-RHS is operationally stable under the most unfavorable load case. 
Standard methodology for experimental studies of DF-RHS on threepoint bending by applied force with continuous video recording of test process to obtain the dependence between the load value and the deflection of the section was improved. Statistical processing of the measurement results of the section walls thickness was preliminary conducted. The graphical and analytical dependences of the deflection of the section under the options of loading on a larger web and on a smaller web from the load magnitude were obtained. The analysis of graphical dependencies revealed that despite $4.8 \%$ smaller thickness of DFW-RHS in comparison with DFRHS, the deflection for the most unfavorable load case (on the larger web) is reduced by $59 \%$, and on the load on the smaller web the deflection is reduced by $0.7 \%$.

The presence of the weld increases the stiffness and strength of the RHS. DFW-RHS will allow to achieve the required parameters of the section stiffness while reducing the thickness of the initial strip, i.e. by saving of workpiece metal. For the most unfavorable option of loading to the RHS larger web, when the non-welded gap is on lateral side, the option of forming a weld will give an improvement in the stiffness of at least $50 \%$. Thus, changing the manufacturing process from DF-RHS to DFW-RHS will improve stiffness and keep strength values at a sufficient level.

\section{SUMMARY}

The paper implements a method for analyzing the stress-strain state of rectangular hollow sections (RHS) by finite-element modeling (FEM) of tests for three-point bending and torsion. Experimental research has also been carried out for three-point bending test, repeating the corresponding simulation. Design schemes, 3-d computer-assisted solid-state and deformable models have been developed using CAD/CAE system software, made it possible to obtain equivalent stress distributions and displacements in RHS models. A simulation of tests for three-point bending and torsion and the tests themselves for three-point bending was carried out for RHS with a cross section of $40 \mathrm{~mm} \times 50 \mathrm{~mm}$ manufactured in two options: (a) by directforming of galvanized steel strips on roll-forming mill in a semi-closed section with a longitudinal gap of $0.5 \mathrm{~mm}$ between the edges formed on a $40 \mathrm{~mm}$ web (DF-RHS); (b) similar direct-forming to the closed section and next welding the edges to a longitudinal weld along the web middle of $50 \mathrm{~mm}$ (DFW-RHS). RHS with various wall thicknesses $(\mathrm{t}=1.93 \mathrm{~mm}$, $1.84 \mathrm{~mm}$ and $0.7 \mathrm{~mm}$ ) was investigated by simulation, given the design features that depend on the manufacturing processes of structural sections. Experimental investigation was performed using photo-video shooting. As a result, the graphs and analytical equations for relating the force $(\mathrm{P})$ and deflection (f) at static load on $50 \mathrm{~mm}$ and $40 \mathrm{~mm}$ webs were obtained, and 
revealed the advantages of DFW-RHS by stiffness and strength. It is shown that the DFW-RHS design will allow to increase stiffness by at least 50\%, reduce the wall thickness by $61.9 \%$ while maintaining the same stiffness and ensuring the high strength indices for the case of least favorable loading on the larger web, i.e. the maximum stresses in the webs RHS will be 2.33 times less than the yield stress of low-carbon steel.

\section{REFERENCES}

1. Wardenier J., Packer J. A., Zhao X.-L., van der Vegte G. J. Hollow sections in structural applications. CIDECT. Geneva, Switzerland, 2010.

2. Huang Y., Young B. Experimental and numerical investigation of cold-formed lean duplex stainless steel flexural members. Thin-walled Structures. 2013. Vol. 73. P. 216-228. DOI: https://doi.org/10.1016/ j.tws.2013.07.019

3. Sun M., Packer J.A. Direct-formed and continuous-formed rectangular hollow sections. Comparison of static properties. Journal of Constructional Steel Research. 2014. Vol. 92. P. 67-78. DOI: https://doi.org/10.1016/j.jcsr.2013.09.013

4. Bock M., Arrayago I., Real E. Experiments on cold-formed ferritic stainless steel slender sections. Journal of constructional steel research. 2015. Vol. 109. P. 13-23. DOI: https://doi.org/10.1016/j.jcsr.2015.02.005

5. Analytical and Statistical Evaluation of FRC Bending Tests Layouts / A. Podstawka at al. Advanced Materials Research. 2015. Vol. 1106. P. 118-121. DOI: https://doi.org/10.4028/www.scientific.net/AMR.1106.118

6. Kuchta K., Tylek I. Rational application of hot finished rectangular hollow sections in steel structures. MATEC Web of Conferences. 2018. Vol. 163. P. 07005. DOI: https://doi.org/10.1051/matecconf/201816307005

7. Flexural behaviour of hot-finished high strength steel square and rectangular hollow sections / J. Wang at al. Journal of Constructional Steel Research. 2016. Vol. 121. P. 97-109. DOI: https://doi.org/10.1016/ .jcsr.2016.01.017

8. Bending angle calculation in the instrumented three-point bending test / P. Larour at al. Proc. IDDRG 2012: Lightweight: Possibilities \& Challenges. Mumbai, India, 2012. P. 203-215.

9. Devi S.V., Singh T.G., Singh K.D. Cold-formed steel square hollow members with circular perforations subjected to torsion. Journal of Constructional Steel Research. 2019. Vol. 162. P. 105730. DOI: https://doi.org/10.1016/j.jcsr.2019.105730

10. Gunalan S., Mahendran M. Improved design rules for fixed ended cold-formed steel columns subject to flexural-torsional buckling. ThinWalled Structures. 2013. Vol. 7. P. 1-17. DOI: https://doi.org/ 10.1016/j.tws.2013.06.013 
11. The optimisation of cold rolled formed products / M.A. Castelucci at al. Thin-Walled Structures. 1997. Vol. 29 (1-4). P. 159-174. DOI: https://doi.org/10.1016/S0263-8231(97)00020-7

12. Yoon K., Lee Y., Lee P.-S. A continuum mechanics based 3-D beam finite element with warping displacements and its modeling capabilities. Structural Engineering and Mechanics. 2012. Vol. 43 (4). P. 411-437. DOI: https://doi.org/10.12989/sem.2012.43.4.411

Information about the author: Kukhar V. V.,

Doctor of Technical Sciences, Professor,

Head of Metalforming Department Pryazovskyi State Technical University 7, Universytetska str., Mariupol, Donetsk region, 87555, Ukraine 